\begin{tabular}{l} 
JOURNAL OF APPLIED MECHANICAL \\
ENGINEERING AND RENEWABLE \\
ENERGI (JAMERE) \\
ISAS Vol. 1 No. 1, Februari $2021.1-5 \quad$ e-ISSN 2775-1031 \\
\hline
\end{tabular}

\title{
Perancangan Mesin Centrifugal Untuk Optimalisasi Tenaga Sortir Sampah Plastik
}

\author{
Darsini $^{1}$, Yustinus Nandha Dian $^{2}$, Suprapto $^{3}$ \\ 1,2,3 Jurusan Teknik Industri, Fakultas Teknik, Universitas Veteran Bangun Nusantara Sukoharjo \\ ${ }^{1}$ dearsiny@yahoo.com*, ${ }^{2}$ nandadianprakoso@gmail.com, ${ }^{3}$ supraptodd@yahoo.com
}

\begin{abstract}
PT. XXX as the yield management company becomes a plastic seed product that is ready to be used as raw material in other plastic companies. Apart from the garbage production of PT. Garuda Prima Sentosa also gets unused plastic waste from domestic and foreign suppliers. In the process of processing plastic waste, still uses the sorting power manually obtained by 40 people, the results obtained are also less than the maximum there are still many other materials mixed in plastic waste from $4200 \mathrm{~kg}$ of plastic waste can only be repaired by other unused material as much as $915.92 \mathrm{~kg}$ per day. This study discusses the centrifugal machine as a separator between used plastic waste from other unused materials and minimizes the sorting power of 40 people to 8 people, and adds the unused material to $1355,308 \mathrm{~kg}$ per day. The design of this Centrifugal machine to be able to overcome the problems that exist in the sorting section so that it can produce cleaner plastic seeds and improve the sorting process.
\end{abstract}

Keywords: Centrifugal machine design, Optimization, Sorting, Plastic waste

\begin{abstract}
Abstrak
PT. XXX mendapatkan sampah-sampah plastik yang tidak terpakai dari supplier penyedia sampah-sampah dalam negeri maupun sampah-sampah dari luar negeri. Dalam proses pengolahan sampah plastik ini, PT. XXX masih menggunakan tenaga sortir secara manual yang berjumlah 40 orang, hasil yang diperoleh juga kurang maksimal karena masih banyak material lain yang tercampur dalam sampah plastik dari $4200 \mathrm{~kg}$ sampah plastik hanya dapat memisahkan material lain yang tidak terpakai sebanyak $915,92 \mathrm{~kg}$ per harinya. Penelitian ini bertujuan untuk merancang mesin Centrifugal sebagai alat pemisah antara sampah plastik yang terpakai dari material lain yang tidak terpakai serta meminimalisir tenaga sortir sebanyak 40 orang menjadi 8 orang, dan memaksimalkan pemisahan material yang tidak terpakai menjadi $1355,308 \mathrm{~kg}$ per hari. Dari perancangan mesin Centrifugal ini mampu mengatasi masalah yang ada pada bagian sortir sehingga dapat menghasilkan biji plastik yang lebih bersih dan mempercepat proses penyortiran.
\end{abstract}

Kata kunci: Perancangan mesin centrifugal, Optimalisasi, Sortir, Sampah plastik

\section{Pendahuluan}

PT XXX adalah perusahaan yang bergerak dibidang pengolahan sampah plastik yang memproduksi biji plastik. PT. XXX dalam proses produksinya mampu mengolah sampah plastik sebanyak 2-4 ton per harinya dan sering menemukan berbagai material yang tercampur dalam sampah plastik tersebut dan harus dipisahkan, supaya dapat diproses menjadi biji plastik, maka diperlukan mesin centrifugal yang bertujuan membantu proses pernyortiran untuk mengurangi banyaknya material lain yang tercampur di dalam sampah plastik sehingga dapat dipisahkan menjadi lebih bersih dan mudah diproses untuk mempercepat waktu sortir, serta mengoptimalkan tenaga sortir yang ada.

\section{Tinjauan Pustaka}

Menurut Waharawichanant [1], Sentrifugasi secara umum dapat diartikan sebagai proses pemisahan dengan menggunakan gaya sentrifugal sebagai driving force. Pemisahan dapat dilakukan terhadap fasa padat cair tersuspensi maupun campuran berfasa cair-cair atau padat-cair. Dua cairan yang dipisahkan dengan metode sentrifugasi biasanya berbentuk dua fasa cair yang teremulsi. 
Dalam penelitian yang dilakukan oleh [2], [3], pada pengolahan minyak kelapa, sering juga dilakukan 3. modifikasi khususnya dalam pemisahan krim untuk mendapatkan bagian minyak. Alat yang digunakan adalah jenis disk bowl centrifuge. Disk bowl centrifuge merupakan alat yang berfungsi untuk memisahkan dua fasa cair dalam suatu proses kontinyu dengan menggunakan gaya centrifugal.

Menurut [4] pemanfaatan gaya sentrifugal juga dapat digunakan dalam perancangan pompa-pompa sentrifugal. Pada dasarnya prinsip kerja pompa adalah membuat tekanan rendah pada isap, sehingga fluida akan terhisap masuk dan mengeluarkannya pada sisi tekan atau sisi keluar dengan tekanan yang lebih tinggi,

\section{Centrifugal}

Menurut [5] Centrifugal adalah suatu gaya yang arahnya menjauhi poros atau benda yang berputar. Gaya centrifugal akan menyebabkan suatu benda melawan gravitasi sehingga benda tersebut tidak jatuh kebawah. Besar kecilnya gaya centrifugal yang dihasilkan tergantung besar kecilnya massa benda atau semakin cepat putaran benda maka akan semakin besar gaya tersebut.

\section{Cara Kerja Mesin Centrifugal}

Menurut Cara kerja mesin centrifugal dijalankan oleh separator centrifugal. Separator sendiri artinya adalah pemisah. Prinsip kerjanya dengan cara memutar suatu larutan atau benda lain kedalam sebuah separator. Larutan atau benda memiliki massa jenis yang lebih berat akan terlempar ke pinggir dan keluar melalui corong buangan. Larutan atau benda lain yang memiliki massa jenis rendah akan berada di bagian tengah dekat dengan poros dan akan keluar disaluran dekat poros [6][8].

Adapun tujuan dalam penelitian ini adalah bagaimana merancang mesin centrifugal guna mengoptimalkan tenaga agar sehingga mampu memisahkan sampah dan material yang tidak terpakai selama proses produksi berlangsung.

\section{Metodologi Penelitian}

Obyek penelitian ini adalah mesin centrifugal yang dirancang untuk kebutuhan perusahaan sampah plastik di PT. XXX untuk memisahkan sampah plastik dari material-material lain.

Tahapan Penelitian

1. Pengumpulan Data

Data perencanaan awal yang digunakan dalam perancangan mesin centrifugal.

2. Pengolahan Data

a. Perancangan dan perencanaan baling-baling yang digunakan sebagai pemisah antara sampah plastik dan material lain.

b. Perencanaan poros dan pasak menggunakan motor dengan spesifikasi sebesar :

$$
\begin{aligned}
& \mathrm{P}=2200 \mathrm{~W}=22 \mathrm{~kW} \\
& \mathrm{n}=750 \mathrm{rpm}
\end{aligned}
$$

c. Perencanaan Bantalan Gelinding

\section{d. Perencanaan Sabuk dan puli}

. Perancangan

Tahapan perancangan gambar mesin centrifugal dimulai dari komponen sebagai berikut:
a. Rangka
b. Baling-baling
c. Saringan sampah plastik
d. Penutup atas
e. Pulley dan Van Belt

4. Analisis Hasil

Membandingkan hasil proses sortir sampah plastik, jumlah tenaga kerja, penyusutan bahan baku, waktu pengerjaan, dan hasil dari pemisahan antara tenaga sortir manual dengan menggunakan alat bantu mesin centrifugal.

5. Kerangka Alur Penelitian

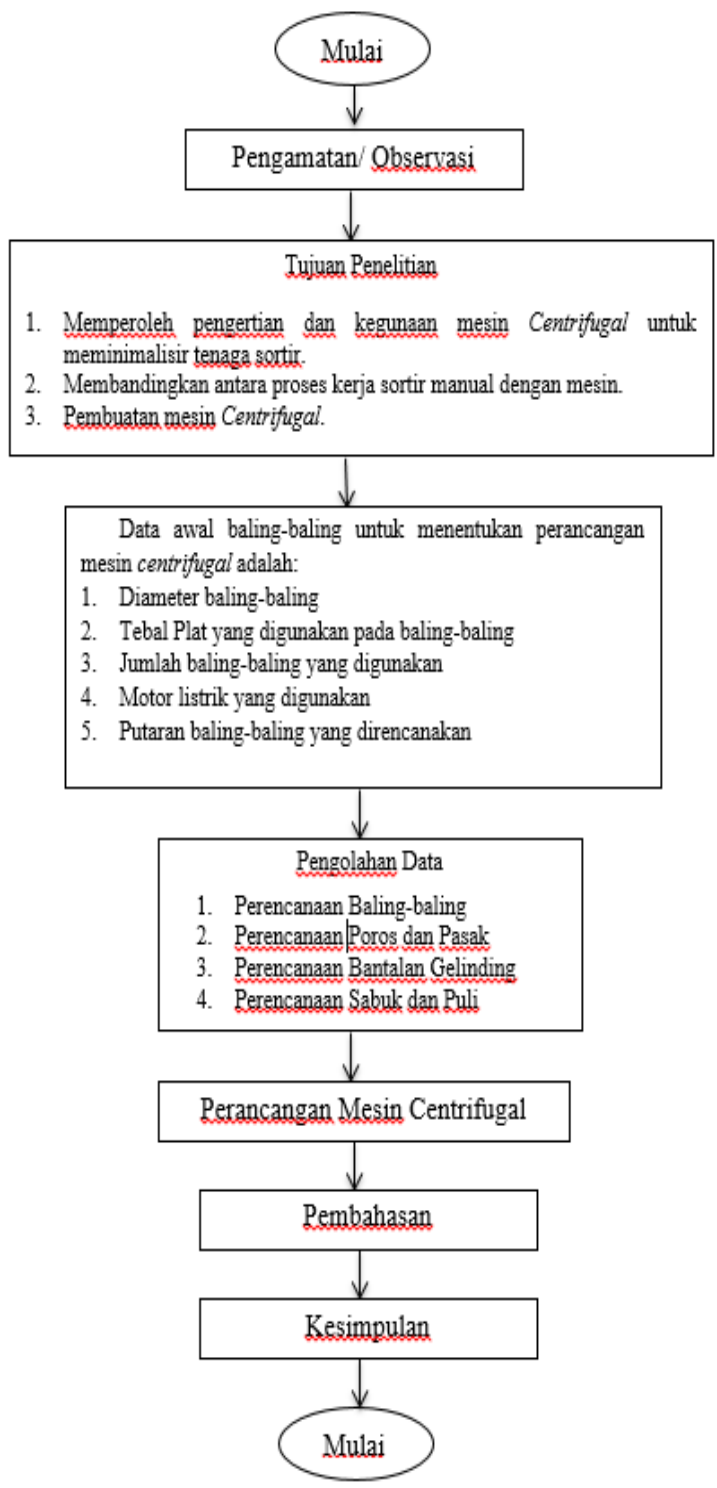

Gambar 1. Diagram Alir Proses Kerja Penelitian 


\section{Hasil dan Pembahsan}

\section{a. Hasil}

Perencanaan Baling-baling

Tabel 1. Data Perancangan Baling-Baling Pemisah

\begin{tabular}{cll}
\hline No & \multicolumn{1}{c}{ Deskripsi } & \multicolumn{1}{c}{ Ukuran } \\
\hline 1 & Diameter & $750 \mathrm{~mm}$ \\
2 & Tebal & $10 \mathrm{~mm}$ \\
3 & Luas penampang & $325 \times 1620=526.500 \mathrm{~mm} 2$ \\
& baling-baling & \\
4 & Total luas penampang & $526.500 \times 4=2.106 .000 \mathrm{~mm}^{2}=$ \\
& (A) & $210,6 \mathrm{~cm}^{2}$ \\
\hline
\end{tabular}

Perencanaan Poros dan Pasak

1) Daya dan putaran yang ditransmisikan pada poros untuk memutar baling-baling sebesar:

$$
\begin{aligned}
& P=2200 \mathrm{~W}=22 \mathrm{~kW} \\
& n=750 \mathrm{rpm}
\end{aligned}
$$

2) Pemilihan Faktor Koreksi

Faktor koreksi $\left(f_{c}\right)$ yang dipilih adalah sebesar 1.0 dikarenakan daya maksimum yang diperlukan. Berikut nilai faktor koreksi yang di tranmsisikan

Tabel 2. Faktor Daya yang Ditransmisikan

\begin{tabular}{lc}
\hline \multicolumn{1}{c}{ Daya yang akan di transmisikan } & $\mathrm{Fe}$ \\
\hline Daya rata- rata yang diperlukan & $1,2-2,0$ \\
Daya maksimum yang diperlukan & $0,8-1,2$ \\
Daya Normal & $1,0-1,5$
\end{tabular}

3) Daya Rencana

$$
\begin{aligned}
& P_{c=f_{c}} \cdot P \\
& P_{c}=1,0.22 \mathrm{~kW}=22 \mathrm{~kW}
\end{aligned}
$$

4) Momen Puntir Rencana

$$
\begin{aligned}
T & =9,74 \times 10^{5} \frac{P_{d}}{n_{1}} \\
T & =9,74 \times 10^{5} \times \frac{22}{750}=28.570 \\
T & =28.570 \mathrm{~kg} / \mathrm{mm}
\end{aligned}
$$

5) Pemilihan Bahan Konstruksi Poros

Bahan poros yang digunakan untuk konstruksi ini yaitu baja karbon konstruksi mesin (JIS G 4501) [9], dapat dilihat pada Tabel 3, dengan nilai kekuatan Tarik $48 \mathrm{~kg} / \mathrm{mm}^{2}$.

Tabel 3. Bahan Material Poros

\begin{tabular}{lcccc}
\hline $\begin{array}{c}\text { Standar } \\
\text { dan } \\
\text { Macam }\end{array}$ & $\begin{array}{c}\text { Lamban } \\
\mathrm{g}\end{array}$ & $\begin{array}{c}\text { Perlakua } \\
\mathrm{n} \\
\text { Panas }\end{array}$ & $\begin{array}{c}\text { Kekuatan } \\
\text { Tarik } \\
\left(\mathrm{kg} / \mathrm{mm}^{2}\right)\end{array}$ & $\begin{array}{c}\text { Ketera } \\
\text { ngan }\end{array}$ \\
\hline Baja & S30C & Pernorma & 48 & - \\
Karbon & S35C & lan & 52 & - \\
Konstruks & S40C & - & 55 & - \\
i Mesin & & - & & \\
(JIS 4501) & & & & \\
\hline
\end{tabular}

6) Tegangan Geser yang Diizinkan

$$
\tau_{a}=\frac{48\left(\mathrm{~kg} / \mathrm{mm}^{2}\right)}{6 \times 1,3}=6,15^{\mathrm{kg}} /_{\mathrm{mm}^{2}}
$$

7) Faktor Koreksi untuk Momen Puntir

Faktor koreksi untuk momen puntir $\left(K_{t}\right)$ diambil nilai sebesar 1,0 sampai 1,5 dikarenakan pada saat beroperasi poros dikenakan sedikit beban kejut atau tumbukan. Faktor lenturan $\left(C_{b}\right)$ diambil nilai 1,2 sampai 2,3 karena akan terjadi beban lentur saat poros beroperasi atau berputar.

8) Diameter Poros

9) Tegangan Geser

$$
\begin{aligned}
d_{S} & =\left[\frac{5,1}{\tau_{a}} K_{t} C_{b} T\right]^{1 / 3} \\
d_{S} & =\left[\frac{5,1}{6,15} 10 \times 1,5 \times 28570\right]^{1 / 3} \\
d_{s} & =[\sqrt[3]{355.382,927}]^{1 / 3}=70,83^{3 x \frac{1}{3}} \\
& =70,83=70 \mathrm{~mm}
\end{aligned}
$$

$$
\begin{aligned}
\tau & =\frac{5,1 \times T}{d_{s}{ }^{3}} \\
\tau & =\frac{5,1 \times 28570}{70^{3}} \\
\tau & =\frac{145707}{343000} \\
\tau & =0,424 \mathrm{~kg} / \mathrm{mm}^{2}
\end{aligned}
$$

10) Koreksi Konstruksi Aman

$$
\begin{aligned}
& \tau_{a}>\tau \\
& 6,15 \mathrm{~kg} / \mathrm{mm}^{2}>0,424 \mathrm{~kg} / \mathrm{mm}^{2} \rightarrow \text { Konstruksi }
\end{aligned}
$$
aman

Pemilihan Pasak

1) Gaya Tangensial pada Pasak

$$
\begin{aligned}
& F=\frac{T}{D_{S} / 2} \\
& F=\frac{28570}{70 / 2} \\
& F=816,3 \mathrm{Kg}
\end{aligned}
$$

2) Dimensi Pasak

$$
\begin{aligned}
& b=18 \mathrm{~mm} \\
& h=11 \mathrm{~mm} \\
& l=150 \mathrm{~mm}
\end{aligned}
$$

3) Tegangan Geser yang Terjadi

$$
\begin{aligned}
\tau_{k} & =\frac{F}{b . l} \\
\tau_{k} & =\frac{816,3 \mathrm{Kg}}{18.150} \\
\tau_{k} & =\frac{816,3 \mathrm{Kg}}{2700} \\
\tau_{k} & =0,302 \mathrm{~kg} / \mathrm{mm}^{2}
\end{aligned}
$$

4) Bahan Konstruksi Pasak

Untuk pasak, umumnya dipilih bahan yang mempunyai kekuatan tarik $60\left(\mathrm{~kg} / \mathrm{mm}^{2}\right)$. 
5) Tekanan Permukaan yang Terjadi

$$
\begin{aligned}
P & =\frac{F}{l x t} \\
P & =\frac{816,3}{11 \times 150} \\
P & =0,495 \mathrm{~kg} / \mathrm{mm}
\end{aligned}
$$

6) Koreksi Konstruksi Aman

$$
\begin{aligned}
& \tau k_{a}=\frac{\sigma_{b}}{S f_{1} x S f_{2}} \\
& \tau k_{a}=\frac{48 \mathrm{~kg} / \mathrm{mm}^{2}}{6 x 2} \\
& \tau k_{a}=4 \mathrm{Kg} / \mathrm{mm}^{2} \\
& \tau k_{a} \geq \tau_{k} \\
& 4 \mathrm{~kg} / \mathrm{mm}^{2} \geq 0,302 \mathrm{~kg} / \mathrm{mm}^{2} \\
& \rightarrow \text { Konstruksi Aman } \\
& P_{a} \geq P \\
& 10 \mathrm{~kg} / \mathrm{mm}^{2} \geq 0,495 \mathrm{~kg} / \mathrm{mm}^{2}
\end{aligned}
$$

\section{$\rightarrow$ Konstruksi Aman}

Perencanaan Bantalan Gelinding

1) Gaya Tangensial yang Timbul

$$
\begin{aligned}
& w_{0}=F_{t}=\frac{2 . T}{d_{s}} \\
& w_{0}=F_{t}=\frac{2 x 28570 \mathrm{~kg} / \mathrm{mm}^{2}}{50 \mathrm{~mm}} \\
& w_{0}=\frac{57140}{50} \\
& w_{0}=1142,8
\end{aligned}
$$

2) Gaya Radial pada Bantalan

$$
\begin{aligned}
& F r=F_{t b} \cdot \tan \propto_{o} \\
& F r=571,4 \cdot \tan 33^{\circ} \\
& F r=571,4 \cdot 0,65 \\
& F r=371,07 \mathrm{kgf}
\end{aligned}
$$

3) Pemilihan Bantalan

Menggunakan tipe 22210E.

4) Beban Equivalen pada Bantalan

$$
\begin{aligned}
& P_{r}=X \cdot V \cdot F_{r} \\
& P_{r}=0,56 \cdot 1 \cdot 371,07 \\
& P_{r}=207,8 \mathrm{kgf}
\end{aligned}
$$

5) Faktor Umur Bantalan

$$
\text { Faktor kecepatan } \begin{aligned}
f_{n} & =\left(\frac{33,3}{n}\right)^{1 / 3} \\
f_{n} & =\left(\frac{33,3}{750}\right)^{1 / 3} \\
f_{n} & =0,076 \\
f_{h} & =f_{n} \cdot \frac{c}{P_{r}} \\
f_{h} & =0,076 \cdot \frac{10911}{207,8}
\end{aligned}
$$

$$
\begin{aligned}
& f_{h}=3,99 \\
& L_{h}=500 \cdot f_{h}{ }^{3} \\
& L_{h}=500 \cdot 3,99^{3} \\
& L_{h}=31760,6 \mathrm{jam}
\end{aligned}
$$

Perencanaan Sabuk dan Pulley

Data Perencanaan Awal
a. Daya : $22 \mathrm{~kW}$
b. Putaran poros $n_{l}: 1500 \mathrm{rpm}$
c. Putaran poros $n_{2}: 1125 \mathrm{rpm}$
d. Putaran poros $n_{3}: 750 \mathrm{rpm}$
e. Putaran poros $n_{4}: 75 \mathrm{rpm}$

1) Pemilihan Sabuk

Berdasarkan daya rencana $22 \mathrm{~kW}$ dan putaran puli 1500 rpm, maka dipilih sabuk-V tipe C.

2) Diameter Nominal Puli

3) Perbandingan Putaran

a. Perbandingan putaran 1

$$
\begin{aligned}
& \frac{n_{1}}{n_{2}}=i_{1} \\
& \frac{1500}{1125} \text { rpm }=i_{1} \\
& i_{1}=1,3
\end{aligned}
$$

b. Perbandingan putaran 2

$$
\begin{aligned}
& \frac{n_{2}}{n_{3}}=i_{2} \\
& \frac{1125}{750}=1,5 \\
& i_{2}=1,5
\end{aligned}
$$

4) Diameter Lingkaran Jarak Bagi

$$
d_{p}=d_{\min } x i
$$

a. Diameter puli besar poros 1

$$
\begin{aligned}
& d_{p}=d_{\text {min }} \times i \\
& d_{p 1}=230 \times 1,3 \\
& d_{p 1}=300 \mathrm{~mm}
\end{aligned}
$$

c. Diameter puli besar poros 2

$$
\begin{aligned}
& d_{p 2}=d_{\min } x i_{2} \\
& d_{p 2}=100 \times 1,5 \\
& d_{p 2}=150 \mathrm{~mm}
\end{aligned}
$$

5) Kecepatan Linier Sabuk V

a. Kecpatan sabuk pada puli penggerak 1

$$
\begin{aligned}
& V=\frac{\pi x d_{\text {min }} \times n_{1}}{60 \times 1000} \\
& V=\frac{3,14 \times 230 \times 1500}{60 \times 1000} \\
& V=\frac{1.083 .300}{60.000} \\
& V=18,055 \\
& V=18 \mathrm{~m} / \mathrm{s}
\end{aligned}
$$


b. Kecepatan sabuk pada puli penggerak 2

$$
\begin{aligned}
V & =\frac{\pi \times d_{\min } \times n_{2}}{60 \times 1000} \\
V & =\frac{3,14 \times 100 \times 750}{60 \times 1000} \\
V & =\frac{235.500}{60.000} \\
V & =3.925 \\
V & =4 \mathrm{~m} / \mathrm{s}
\end{aligned}
$$

6) Menentukan Tipe dan Ukuran Sabuk

Tipe dan ukuran sabuk antara pulley poros penggerak dan pulley poros yang digerakkan adalah C. 2700 .

\section{Perancangan Mesin Centrifugal}

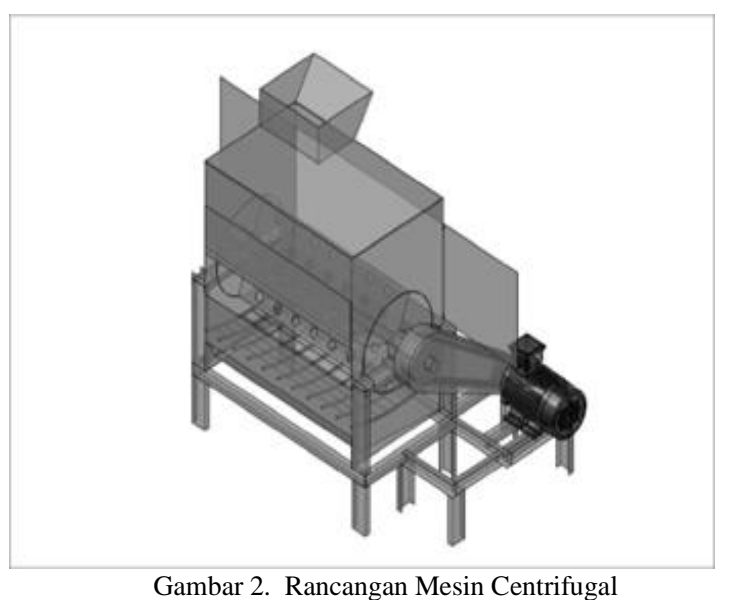

\section{b. Pembahasan}

Perbandingan Proses Kerja Mesin dan Sortir Manual Output yang Dihasilkan

Tenaga sortir manual hanya dapat memisahkan material-material padat sedangkan material cair dan lumpur tidak bisa dipisahkan serta masih terdapat material lain yang ikut tercampur sehingga susah untuk diproses. Proses sortir yang menggunakan mesin centrifugal mampu memisahkan berbagai macam

\begin{tabular}{|c|c|c|c|}
\hline No. & Uraian & Sebelum & Sesudah \\
\hline 1. & $\begin{array}{l}\text { Jumlah } \\
\text { Tenaga } \\
\text { Kerja }\end{array}$ & 37 orang & 8 orang \\
\hline 2. & $\begin{array}{l}\text { Hasil } \\
\text { penyortiran }\end{array}$ & $3284,08 \mathrm{~kg}$ & $2844,692 \mathrm{~kg}$ \\
\hline 3. & $\begin{array}{l}\text { Sampah } \\
\text { yang tidak } \\
\text { terpakai }\end{array}$ & $\begin{array}{l}4200 \mathrm{~kg} \mathrm{-} \\
3284,08 \mathrm{~kg} \\
=915,92 \mathrm{~kg}\end{array}$ & $\begin{array}{l}4200 \mathrm{~kg}- \\
2844,692 \mathrm{~kg} \\
=1355,308 \mathrm{~kg}\end{array}$ \\
\hline
\end{tabular}
material lain, sehingga sampah plastik dapat lebih bersih dan mudah diproses serta tidak memakan waktu lama saat proses penyortiran.

Tabel 4. Hasil sebelum dan sesudah menggunakan mesin centrifugal.

\section{Kesimpulan}

Dari hasil penelitian ini dapat disimpulkan bahwa perancangan mesin centrifugal ini membutuhkan tenaga kerja sebanyak 8 orang. Mesin tersebut mampu memisahkan sampah dan material yang tidak terpakai sebanyak 1355,308 kg, yang sebelumnya menggunakan tenaga sortir manual sejumlah 37 orang, mesin tersebut dapat memisahkan sampah dan material yang tidak terpakai sebanyak $915,92 \mathrm{~kg}$, dan dapat memisahkan berbagai macam material lain yang tidak dapat diproses dan dipisahkan hanya dengan menggunakan tenaga sortir manual, sehingga untuk mendapatkan hasil yang lebih bersih dan mudah diproses, diperlukan mesin centrifugal ini.

Adapun saran dari perancangan untuk mesin pencacah plastik tipe crusher:

1. Elemen mesin pada mesin pencacah plastik yang dicancang sebaiknya

disesuaikan dengan yang tersedia di pasaran.

2. Tenaga kerja yang tersisa karena peminimalan tenaga sortir dapat dioptimalkan dengan pembagian kerja shift untuk kelancaran proses pernyortiran.

3. Ditambahnya satu unit mesin centrifugal untuk mengomptimalkan proses pernyortiran sehingga hasil yang di peroleh lebih banyak.

\section{Ucapan Terima Kasih}

Terima kasih kami sampaikan kepada PT. XXX yang telah menyediakan tempat dan fasilitas sebagai obyek penelitian.

\section{Daftar Rujukan}

[1] S. Waharawichanant, Centrifugal Separation Process. Chicago: The Scientific Press, 2010.

A. Budiman, "Metode Sentrifugasi Untuk Pemisahan Biodiesel Dalam Proses Pencucian," Jurnal Riset Industri, vol. 3, no. 3. 2009.

[3] A. Budiman, "Sentrifugasi," Jul. 30, 2010. http://beckmanindonesia.blogspot.com (accessed Nov. 19, 2020).

[4] A. H. Church, Pompa dan Blower Sentrifugal, 3rd ed. Jakarta: Erlangga, 1993

5] E. A. Kisnarti and Suryadhi, "Rancang Bangun Mesin Pengering Sentrifugal pada Proses Penggilingan Sampah Plastik Jenis Polyethylene Therephthalate (PET)," Jurnal Sain dan Teknologi, vol. 10, no. 1, 2015.

[6] Sains Teknologi dan Bisnis, "Centrifuge (Centrifugal Separator)," Sains, Teknologi dan Bisnis, Nov. 15, 2014. https://www.caesarvery.com/2014/11/centrifuge-centrifugalseparator.html (accessed Jul. 21, 2018).

[7] Sularso and K. Suga, Dasar Perencanaan dan Pemilihan Elemen Mesin. Jakarta: Pradnya Paramita, 2004.

[8] Sularso, Elemen Mesin. Jakarta: Pradya Paramitha , 1997.

[9] Kogelahar, "Sekilas Tentang SKF," 2014. http://www.kogelahar.com/industry-solution/sekilas-tentangskf (accessed Jul. 21, 2018). 